\title{
THE SYSTEM OF THE CALIBRATION FOR VISIBILITY MEASUREMENT INSTRUMENT UNDER THE ATMOSPHERIC AEROSOL SIMULATION ENVIRONMENT
}

\author{
Zhifeng Shu ${ }^{12^{*}}$, ShaoChen Yang ${ }^{3}$, Wenjing $\mathrm{Xu}^{3}$ \\ ${ }^{1}$ Chinese Academy of Science, Key Laboratory of Geospace Environment, Hefei, Anhui, 230026, \\ China, *Email:szf@ustc.edu.cn \\ ${ }^{2}$ University of Science and Technology of China, School of Earth and Space Science, Hefei, Anhui, \\ 230026, China
}

\section{ShenZhen Darsunlaser Tech Co.,Ltd Shenzhen Guangdong,518067,China}

\begin{abstract}
Visibility is one of the most important parameters for meteorological observation and numerical weather prediction (NWP).It is also an important factor in everyday life, mainly for surface and air traffic especially in the Aeronautical Meteorology. The visibility decides the taking off and landing of aircraft. If the airport visibility is lower than requirement for aircraft taking off stipulated by International Civil Aviation Administration, then the aircraft must be parked at the airport. So the accurate measurement of visibility is very important. Nowadays, many devices can be measured the visibility or meteorological optical range (MOR) such as Scatterometers, Transmissometers and visibility lidar. But there is not effective way to verify the accuracy of these devices expect the artificial visual method. We have developed a visibility testing system that can be calibration and verification these devices. The system consists of laser transmitter, optical chopper, phase-locking amplifier, the moving optic receiving system, signal detection and data acquisition system, atmospheric aerosol simulation chamber. All of them were placed in the atmosphere aerosol simulation chamber with uniform aerosol concentration. The Continuous wave laser, wavelength $550 \mathrm{~nm}$, has been transmitted into the collimation system then the laser beam expanded into $40 \mathrm{~mm}$ diameter for compressing the laser divergence angle before modulated by optical chopper. The expanding beam transmitting in the atmosphere aerosol cabin received by the optic receiving system moving in the $50 \mathrm{~m}$ length precision guide with $100 \mathrm{~mm}$ optical aperture. The data of laser signal has been acquired by phase-locking amplifier every 5 meter range. So the 10 data points can be detected in the
\end{abstract}

50 meters guide once. The slope of the fitting curve can be obtained by linear fitting these data using the least square method. The laser extinction coefficient was calculated from the slope using the Koschmieder formula, then it been divided by 3 is MOR. The aerosol concentration in chamber can be changed by adjusting aerosol generator that producing variety of visibility atmospherical environment. The experiment has been carried out and the measurement accuracy of atmospheric transmittance is $0.3 \%$ Corresponding to the accuracy of MOR $4.9 \%$ at the $2 \mathrm{~km}$ visibility environment. So this system can be calibrated and validated the other visibility measuring devices.

\section{INTRODUCTION}

Visibility is one of the most important parameters for meteorological observation and numerical weather prediction (NWP).It is also an important factor in everyday life, mainly for surface and air traffic especially in the Aeronautical Meteorology ${ }^{[1,2,3]}$. Visibility is the most important information for pilot of landing and taking off aircraft. One of the most complicated phases of flying an aircraft is landing approach. The ground staff provide the pilot the visibility ( the runway visual range RVR). The meteorological visual range(MOR) is most important parameter for composing the RVR. So the accurate measurement of visibility is very important. Nowadays, many devices can be measured the visibility or meteorological optical range (MOR) such as Scatterometers, Transmissometers and visibility lidar. But there is not effective way to verify the accuracy of these devices expect the artificial visual method. We have developed a visibility testing system that can be calibration and verification these devices ${ }^{[4,5]}$. 


\section{METHODOLOGY}

Figure 1 shows that block diagrams of the calibration system. The main container includes a continuous wave (cw) laser with wave length $550 \mathrm{~nm}$ and power $50 \mathrm{mw}$, optical chopper with frequency $20 \mathrm{~Hz}$ to $1 \mathrm{kHz}$, detector with model thorlabs DET100A, motor control, phase-locking amplifier, high precision guide and the optical transceiver system. All of them are placed in the atmosphere aerosol simulation environment with LWH $65 \mathrm{~m} \times 2 \mathrm{~m} \times 2 \mathrm{~m}$. The Continuous wave laser, wavelength $550 \mathrm{~nm}$, has been transmitted into the collimation system then the laser beam expanded into $40 \mathrm{~mm}$ for compressing the laser divergence angle before modulated by optical chopper. The expanding beam transmitting in the atmosphere aerosol cabin received by the optic receiving system moving in the $50 \mathrm{~m}$ length precision guide . The data of laser signal has been acquired by phase-locking amplifier every 5 meters range. So the 10 data points can be detected in the 50 meters guide once.

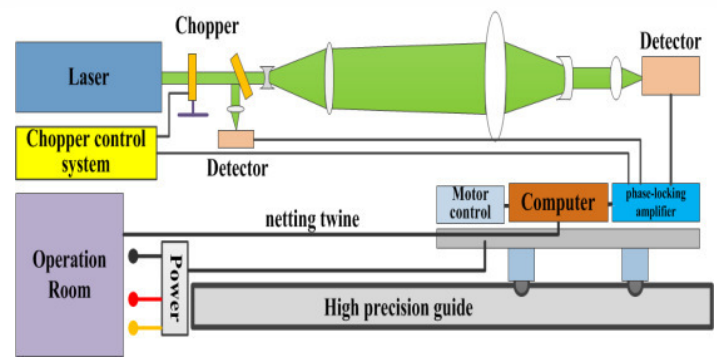

Fig1. The block diagrams of the visibility calibration system

The atmosphere aerosol simulation environment is the transparent glass cabin the all kinds of aerosol can be produced by the aerosol generator such as atomizer aerosol generator, atomizer aerosol generator, black carbon aerosol generator. These generators are placed in a room beside the glass cabin as shown in the figure 2 . The aerosol can be emitted in to the cabin through the nine pipelines with uniform distribution along the guide, then it will be mixed uniformly by the 10 convective fans distributed along the guide. The aerosol concentration can be detected by the concentration to ensure the uniform aerosol distribution in the cabin. Figure 4 is the real pictures and software interface of the system.

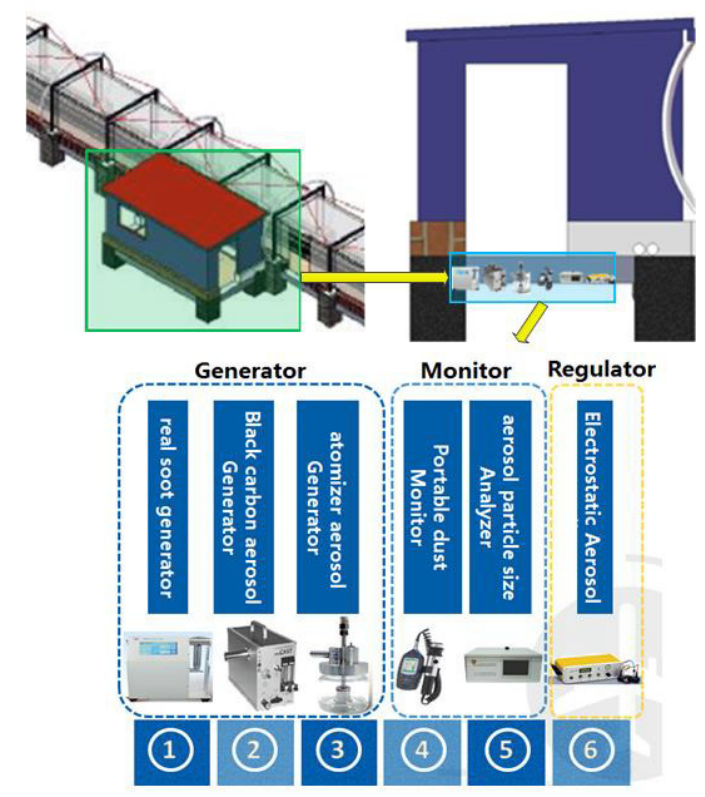

Fig2. Aerosol generation system

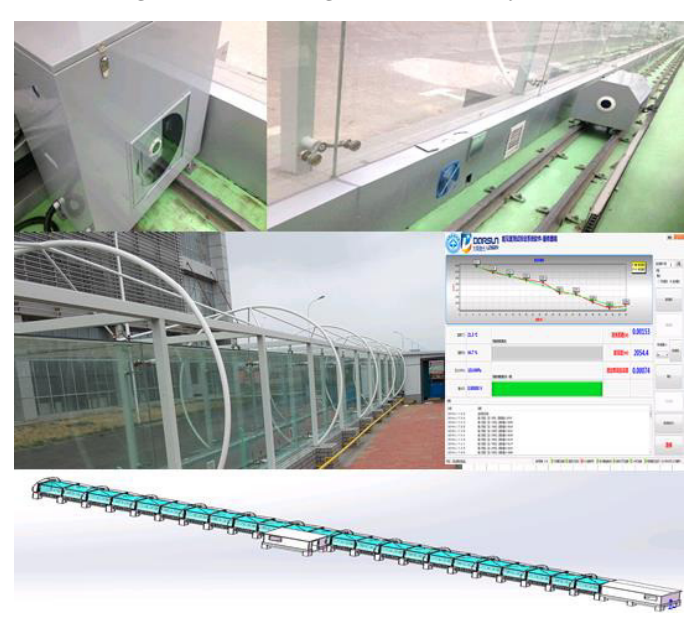

Fig3. The pictures of Atmospheric simulation cabin

\section{RESULTS}

These system of visibility calibration have been built in the tianjin province. In order to testing the performance of the system a experiment has been carried out. Laser beam has been emitted and been chopped then the sigal will be detected by the detector and data acquired by the phase-locking amplifier that they are mounted on the cart. The speed of the cart is $3 \mathrm{~m} / \mathrm{s}$ and it will stay 10 seconds when responsing the position sensor for detecting and acquiring of the data. There will be 10 points data for calculating the MOR. There data can be fitted linearly by the least square method and the slope can be achieved. According 
to the lidar equation, the slope is the laser atmosphere extinction coefficient, then it been divided by 3 is MOR using Koschmieder formula. Figure 4 is the laser energy change when the cart goes and backs along the glass cabin. Fitting these data the slope is $-8.002^{-4}$ Corresponding to $3.6 \mathrm{~km}$ MOR using 3 divide the slope. The standard error of the fitting is $3.11^{-5}$ Corresponding to the of $4.9 \%$ accuracy of MOR as shown in figure4.

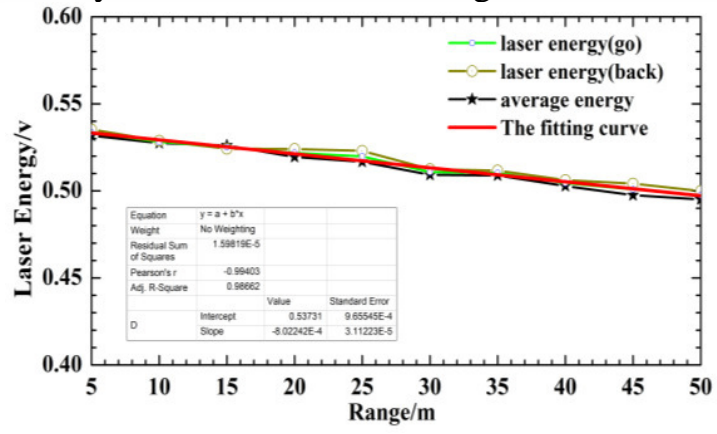

Fig4. The result of the experiment

\section{CONCLUSIONS}

The calibration system for visibility measurement instrument under the aerosol simulation environment has been built and the measuring MOR expriment has been carried out and the accuracy of MOR is $4.9 \%$ at $3.6 \mathrm{~km}$ visibility. The MOR accuracy of the Civil aviation administration is $\pm 50 \mathrm{~m} @ \mathrm{MOR} 10 \mathrm{~m} \sim 500 \mathrm{~m}, \pm$ $10 \% @ M O R>500 \mathrm{~m} \sim 1500 \mathrm{~m}, \pm 20 \%$ @ MOR > $1500 \mathrm{~m} 50000 \mathrm{~m}$. So this system can be used to calibrate and validate the other visibility measuring devices. There system is the first visibility calibration device in the international arena .It can be do some other meteorological research under the atmosphere aerosol simulation environment.

\section{ACKNOWLEDGEMENT}

This work was funded by the National Natural Science Foundation of China (NSFC) project Nos. 41304123 and the civil aviation administration of china.

\section{REFERENCES}

[1] J. Streicher, C.Monkel, H.Borchardt, Trial of slant visual range measuring device, Journal of atmospheric and oceanic technology, Vol 10 718 724,1993.
[2] R.Boers, H.Klen baltink, H.J.Hemink, F.C.Bosveld,M.Moerman, Ground-based observation and modeling of the visibility and radar reflectivity in a radiation fog layer, Journal of atmospheric and oceanic technology, Vol 30 288 299.

[3] M.A.Vanghan, D.M.Winker and K.A.Po-well. "Part2: Feature detection and layer properties algorithms" CALIOP Algorithm Theoretical Basis Document PC-SCI-202 Part2, pp.87.

[4] Jurgen Streicher, Christian Werner. Design of a small laser ceilometers and visibili-ty measuring device for helicopter landi-ng sites[J]. Laser Radar Technology for Remote Sensing, SPIE, Vol.5240:31-41.

[5]. CHEN Min, SUN Dong-song, LI Hong-jing. Detective method and analysis of atmosphere slant visibility for lidar $[\mathrm{J}]$. Infrared and Laser Engineering, Vol 35(2): 156-160.. 